\section{Chlorine Gas Filters in Relation to Reaction Velocity.}

DURING the course of some work which I have been carrying out recently on the photo-synthesis of hydrogen chloride from its elements, rather curious results have been obtained. The light used to activate the chlorine-hydrogen mixture was filtered through varying quantities of chlorine gas with the object of studying the corresponding variations in the reaction velocity. It was found that a very small pressure of chlorine in the filter was able to reduce the actinic power of the light very greatly, but increases of the chlorine pressure produced less and less effect. The curve obtained by plotting actinic power against density of filtering medium was not, however, an exponential function, but more the shape of a rectangular hyperbola which for high densities tended to a definite 'residual' value for the actinic power. A tube of $45 \mathrm{~cm}$. of chlorine at atmospheric pressure reduced the reaction velocity to so per cent. of its initial value.

In conjunction with $\mathrm{Mr}$. A. Elliott, further experiments were carried out using a tube one metre and a half in length, and the curve extended in the direction of still greater concentrations. The residual velocity was then reduced to 5 per cent., and a very similar curve was obtained when a solution of chlorine in carbon tetrachloride was used as the filtering medium instead of chlorine in the gaseous state.

$$
\text { WILFRID TAYLOR. }
$$
(Earl Grey Fellow.)

University of Durham, Armstrong College,

Newcastle-upon-Tyne, September 24.

\section{The Structure of the Continents.}

IN the investigation of the structure of the continental masses there are two important considerations which must not be overlooked.

The first is the inadequate data available for the calculation of the velocity of transmission of vibrations in the earth's crust. Dr. Jeffreys has made excellent use of what little there is, but, as I pointed out at the meeting of the British Association at Bournemouth in I9I9, and as he himself has contended, there is urgent need of systematic experimental work on the times of transmission of such vibrations.

In the second place, experiments on the elasticity and physical characters of hand specimens of rocks is of little value for the determination of those of deepseated magmas of similar composition, not only on account of the enormous pressure that prevails even at moderate depths, but also because of the presence of volatile constituents, consisting largely of the elements of water and (especially in basic rocks) of sulphur compounds, far in excess of those contained in hand specimens of even glassy rocks such as tachylyte. John W. Evans.

Imperial College of Science,

South Kensington: S.W. 7, October 25.

\section{Sterility in the Vegetable Marrow.}

SEEING that a letter on the above subject has recently appeared in Nature (October 23, p. 592), it may be of interest to place on record my experience this summer regarding pumpkins. Besides growing vegetable marrows, which, as it happens, have behaved quite normally this season, bearing an abundant crop, we usually put out a single pumpkin plant and manage, as a rule, to obtain from it one large fruit. For the first time, two plants were put out this year- a piece of good fortune, for one of these declined to produce a single female flower. I had it under strict observation the whole season. The other behaved normally, forming plenty of female flowers and ripening one fruit. The two plants grew side by side under identical conditions of soil and light. Pumpkins have been grown by me for the last six or seven years, and this is the first time a plant has been seen to behave in this way. I have never yet come across a completely male marrow plant.

I fear I can offer no adequate explanation as to the reason for the lack of female flowers in the marrow plants mentioned by Miss Armitage. If the past summer had been cold and sunless, low temperature might have been suggested as the cause; but, as she writes, the season has been favourable for half-hardy plants, and the abundance of marrows formed and matured here point to this. It looks as if the maleness had been innate in the seeds and not induced by external conditions. Blaithwaite,

Wigton, Cumberland, October 25 .

\section{Optics and Poetry.}

"Iam clarum mane fenestras Intrat, et angustas extendit lumine rimas." PERSIUS (A.D. 34-62), Sat. iii. I-2.

"Here is full morning coming through the window shutters, and making the narrow crevices look larger with the light"--(Conington's translation).

THAT a narrow slit seems to grow wider as the intensity of the light coming through it increases is of itself a dry and not very important matter of common observation; but the very charming use of this fact by the Latin poet, as an indication to the sluggard within that he has long overslept the proper hour of rising, gives it a new attraction and interest, and is worth noting. "We go on snoring, enough to carry off the fumes of the unmanageable Falernian, while the shadow is crossing the fifth line of the dial," that is, at eleven o'clock.

This apparent widening of a narrow slit is perhaps due to a kind of dazzle or halation affecting the surface of the retina, comparable to the irradiation or spreading of the light on a photographic plate. After a night in bed the eyes would naturally be more alert to effects of this kind. M. Gustave Le Bon found by experiment that it requires at least fifteen minutes spent in darkness to bring the eyes to their maximum sensitiveness to faint illumination. No doubt the poet had often observed the phenomenon himself as he lay, 'twixt sleep and waking, watching the slits in the shutters, first in the grey dawn and then lit by the sun.

Dublin, October $2 \mathrm{I}$.

\section{'Red Rain' at Bordighera, Italy.}

'RED rain' fell at Bordighera on the morning of October $3 \mathrm{I}$, coating the pavements and vegetation with a dense red-brown deposit which turned to salmon colour when dry. The shower, which terminated about noon (English summer time), was accompanied by a current of hot moist air from the east. The previous day was wet and overcast, and the evening after the shower there was a thunderstorm with long flashes of lightning from east to west at an estimated altitude never touching below 2500 feet. Samples of the deposit (doubtless sand from the Sahara) are being preserved for microscopical examination.

G. H. BRYAN.

Le Lucciole, Bordighera, Italy, November $\mathrm{I}$. 